\title{
A General Introduction
}

This special issue originates from an international lecture series held at Jinan University in Guangzhou, PRC. The lecture series was well received by Chinese and international students. Their enthusiasm inspired the organizer and presenters to discuss further ideas to continue our collaboration. Through our discussion, the idea to organize the presentations into a special issue for a journal emerged. Given the contributors' focus on Africa-China relations (historical and contemporary), we chose to publish in African and Asian Studies for the journal's reputation in providing a platform for discussing the two continents (i.e., Africa and Asia) on equal terms. This special issue aims to bring about new insights and perspectives through cross-fertilization between area studies (broadly defined) in Africa and Asia.

While the above-mentioned lecture series focused on China and the Belt and Road Initiative (BRI), elaborating ways in which the latter builds on existing historical and cultural frameworks (constituted by and constitutive of trade routes, political missions, individual travels, and people's memories and oral stories), this special issue does something similar but attends to China's relations with the Global South, namely African countries. Much has been written on Africa-China (or China-Africa and Sino-Africa) since the early 2000s, on the movements of capital (Adisu, Sharkey, and Okoroafo 2010; Alden 2006; Ayodele and Sotola 2014; Cheung et al. 2012; Lumumba-Kasongo 2007 and 2011), raw and manufactured goods (Akyeampong and Fofack 2019; Oke, Oshinfowokan, and Okonoda 2019; Regissahui 2019), and peoples (Debrah and Asante 2019, Gukurume 2019, Haugen 2019, Obeng 2019). The robust body of work has often undervalued transcultural expressions and imaginaries as well as affinities between the Chinese and African peoples over extended historical periods.

Indeed, China has been a center of cultural production and distribution since antiquity, known as it has been in many parts of the world particularly for its porcelain, silk, and tea industries. In more recent time, China has again become a major economic power that manufactures growing quantities of affordable commodities for export. While this trend has attracted scholarly attention on a more general level (Kusimba, Zhu, and Kiura 2020; Eom, Brautigam, and Benabdallah 2018; Tang 2019), there has so far been little appreciation of the variety of this exchange and of its deeper sociocultural effects, especially in 
countries of the Global South. The BRI, launched by the Chinese government in 2013, has further turned the spotlight on China and these countries, but their connections to one another have long already been forged and sustained in immaterial and material ways.

This special issue is concerned with the immaterial - mainly culture as manifested in artistic transactions, intercontinental travels, everyday people's interactions, transcultural symbols, reception and appropriation of disparate practices, and novel understandings of solidarity - and its part in creating, framing, and exhibiting what could be called an identity of the Global South. This is not to disregard the interconnectedness formed through political and economic engagements but to pay attention also to the mobility and circulation of artifacts (inclusive of commodities and visual and literary arts), ideas, and people (Appadurai 1996).

Global South has become a catch-all concept used to refer to and, even, define the economically poorer parts of the world. To use Walter Mignolo's (2011) phrase, it is "a fashionable expression" (165). Though debates regarding its meaning, utilization, applicability, and analytical value continue in academic circles (Clarke 2018), it remains largely under-theorized. The late Arif Dirlik (2007), intellectual historian of modern China and critic of global capitalism, traced its origin (intellectual, ideological, and political orientation) to the term "Third World" (or Tiers Monde), coined in $195^{2}$ by Alfred Sauvy and popularly used by the radical Left in the 1960s and 1970 .

Since the 199os, global South (with small "g") has been an "idea [that] points to one form of alternative global alliance" (12). The term is contingent on societies of the South (regarded as the periphery, occupied by marginalized and dispossessed groups) inventing themselves through their own initiatives to pursue development, taking command of their own future, and in doing so, also inventing economic alternatives to neoliberalism (15-16). There is a sense of returning to earlier economic and political alignments and alliances (affinities) asserting sovereignty, but development must now be sought in the parameters of an extended global capitalist economy. Within the contemporary context, the ideological and political spaces as well as projects of the South indeed differ from the colonial and immediate post-colonial periods.

Similarly, Mignolo (2011) refers to the Global South not as a particular geography but a metaphor for regions of the world, underdeveloped or negatively impacted by the globalization of capitalism (165). By this, he further points out, the South could be in the North and North in the South. Importantly, Global South is "the place where another way of life is burgeoning" (166) as "global futures are being forged by delinking from the colonial matrix of power" (184). In Mignolo's and Dirlik's theorizations, autonomy to transform the hegemonic 
liberal economic principle is key to the challenges and possibilities facing the Global South.

The special issue builds on such notions of self-determination to examine and theorize the Global South beyond being a historical cultural space whereby aesthetics and everyday life are inseparable from the production of colonial geographies, but as a space of transcultural assemblage (expression and imagination) rendered by increased interactivity among societies of the South. Artifacts, ideas, and people not only circulated between the colonial metropoles and colonies and continue between North and South in the postcolonial era, but also back to and between Southern societies (regions). From different beginning points and methods, each contributor of the special issue asks readers to consider whether the latter movements (i.e., South-to-South) reify a Global South culture that presents cultural alternatives to the hegemonic liberal geoculture of the capitalist world system, which would commoditize and, thus, privatize - all aspects of human society (Kazanjian 2016); and, if so, in what ways?

That the modern capitalist world system is in terminal crisis since the 1960 s is the premise of Abye Assefa's article. Building on the works of worldsystems scholars, such as Giovanni Arrighi, Takeshi Hamashita, and Immanual Wallerstein, Assefa asserts that this crisis is unlike earlier crises of accumulation experienced in that there is no recovery from the world's downward spiral engendered by efforts to control three major costs of the key factors of (re)production worldwide (i.e., labor, inputs, and taxes). These efforts have given rise to social movements all over, focused on employment and wages, environment, and social equality.

Liberalism's promise of economic growth and social progress is essentially falling apart. In a rising sense of pessimism, Assefa further asks if the geoculture of liberalism could in fact adapt to the future; if not, what would replace it? On the one hand, he does not see the "Global South" or, on the other hand, "the rise of China" standing as clear and compelling alternative, reason primarily being that the political ascendancy of the Global South and the economic rise of China (understood from the same capitalist rationale) have been epistemically constructed as discrete phenomena, effectively exteriorizing their relations from one another and entrusting both to the West. Assefa urges us to challenge conventional theories to consider different possibilities for the future, such as foregrounding a longer historical conception of other systems while concurrently interrogating the interstitial processes of the modern capitalist world-system to locate the nexus of the Global South and China, which contain different cultural, political, and economic realities not premised on the endless accumulation of profit. The other side of the terminal crisis of the 
modern capitalist world system that Assefa alludes to is the crisis of Western hegemony worldwide.

T Tu Huynh's article subsequently asks whether it is possible for the people of the South, namely Africans and Chinese, to imagine each other without the West as its geocultural dominance diminishes; and if so, how is this being made possible? In Huynh's analysis, multilateral platforms, such as the Forum on China-Africa Cooperation (FOCAC), directly created by the African and Chinese governments to recognize the African continent's and China's historical relationship and to facilitate smooth operation of economic-centered projects and enhance market understanding offer one important source for investigating ways in which Africa and China are mutually imagining one another, or not. Her article draws attention to the inclusion of people-to-people and cultural exchanges to FOCAC.

Although ranking third among policy priorities (behind economic and political), a significant number of government-sponsored and curated activities (e.g., large-scale art exhibitions, dance and music performances, television programs, and artist exchanges) have taken place in China and in African countries besides the establishment of Confucius Institutes for language and cultural learning in Africa. While important, these events, aimed at educating audiences about different cultures, mainly present a singular discrete culture that is either Chinese or African. This situation mirrors earlier cultural circulations that were deemed undesirable - for example, the encounter between people in a colonial situation that Mary Louise Pratt (1992) calls "the contact zone" where "disparate cultures meet, clash, and grapple with each other, often in highly asymmetrical relations of domination and subordination" (7). That is to say, the government-sponsored events do not acknowledge the fact of cultural coproduction whereby new - or, specifically, Global South - cultures are being collectively created by people from grounded communities directly interacting and interrelating with one another.

Accordingly, Huynh provides three examples to elaborate what she refers to as people's cultural productions, which differs from the governmentsponsored cultural exchanges. Through an in-depth interview with a Chinese photographer-cum-filmmaker and detailed analysis of the works of two African painters, she demonstrates how the visual arts push back and against metanarratives generated by the West and by China that marginalize how broader geopolitical dynamics effect - or become internalized in - local aesthetics and everyday life.

Danson Sylvester Kahyana's article shows that it is not only the visual artists who have a role in interpreting and vernacularizing global geopolitical dynamics, but also writers, such as Taddeo Bwambale Nyondo who, as a result 
of receiving a media scholarship, had the opportunity to travel to China. In China, Nyondo had no agency over his own itinerary: The 30 cities and towns he visited and the (few) people he interacted with were all pre-selected and pre-determined by the sponsor of his journey, thereby limiting his view of Chinese society. The journey resonates with DuBois's made in the 1950s, when he was invited my Mao Zedong as a gesture of solidarity with Africa's diaspora. The visit occasioned a guided tour, seemingly allowing DuBois to witness China's economic transformation (Brown 2016). That DuBois subsequently wrote about China with much reverence reveals the positive impression he acquired from the guided tour.

Similar to DuBois, Nyondo wrote about his travel through China and maintained a highly positive perspective of the country's economic development in such a way that, Kahyana points out, reflects the writer's own national consciousness, of Uganda as a place of deficit that could benefit from modeling after China. On the one hand, Kahyana's analysis of Nyondo's travel and travelogue (and online interviews with him) reveals a continuation of over half a century's diplomatic relations between China and Africa. On the other hand, Kahyana provides a view of South-South perspective that is asymmetrically created and replete with silences or gaps: The South that is Uganda and Africa, generally, are demarcated by Nyondo's subaltern position in the guided tour and the South that is China is not really known in spite the South-South engagements in place. That everything was paid for by his sponsor, undoubtedly defined what Nyondo would/could write about China. That is to say, in Kahyana's view, the journey was already biased from the start to finish, beginning and ending in Uganda.

Turning to South Africa, Natalia Molebatsi and T Tu Huynh's article interweaves local memory, oral stories, and history to challenge popular belief that the Black people had little to no interactions with the Chinese people, who have been in the country for at least three generations. The power of oral histories and memory strategies is that they "offer less mediated stories in ways that allow the teller of the story to speak in her own voice." The article is organized around Natalia's grandmother's (re)memory and stories of her encounters and interactions with the Chinese people in Alexandra, a township in present-day Gauteng Province, when the apartheid system was introduced by the all-White government into the country's legal framework and implemented in the 1950s to the early 1970s. During this period, people were forced to see the world through Black and White and live divided lives. As such, the stories recounted in the article not only give local texture to a group of people who came from afar (i.e., China) to make their own living in South Africa, but also reveal how Black and Chinese people did not all readily comply with legislations that 
racially categorized and restricted where they could live and what they could do - at least in the early phase of apartheid.

The community Chinese butcher and the Chinese man who ran the fafi gambling game, referred to as "mo-China" among the Black people who were the primary players, stand out for their important connections to Black women's everyday struggles to reproduce their livelihoods under the apartheid system. They elucidate the relevance of having a holistic (intersectional) view of apartheid, whereby racism was not the only barrier in poor Black women's lives but also patriarchy and class. According to the authors, though fafi was illegal, it supplemented Black women's, including Natalia's grandmother, exploitatively low income from their work as domestic servants in White households; and it was also income for the Chinese persons (usually men) who administered the game. Such stories, crossing and informing worlds, were prohibited and continue to be prohibited knowledge that requires new attention as we consider possibilities for South-South engagements without a dominant Western intermediary.

Building on Norman Fairclough's integrative approach to discourse analysis that engages with social theoretical issues and networking of social practices, Binjun Hu's article explores how cultural practices travel and get translated in different locations. Through semi-structured, open-ended interviews with Chinese entrepreneurs in one of Johannesburg's two Chinatowns, Hu investigates how the cultural symbol of Zhaocaimao (Lucky Cat) has travelled from China to South Africa, and how it has been creatively appropriated by Chinese immigrants in this country in different spaces like art exhibitions, shops, and homes, to mention but a few. She shows that the symbol serves myriad purposes, including linking the Chinese people of different eras and locations, for instance, the Chinese of the folkloristic period who believed in a God of Wealth and the Chinese immigrants in South Africa.

That Zhaocaimao has been appropriated by different people, both in name and substance, but with some modifications, is evidence that it is a dynamic symbol that is capable of taking on a multiplicity of identities, including hyphenated ones like Afro-Chinese or Sino-African, that the work of Pretoria-based artist Cobus Haupt makes possible. One of the implications of this, Hu shows, is that the meaning-making practices associated with Zhaocaimao have the power to distinguish between the South African-born Chinese and the new Chinese immigrants, since they relate to the symbol in different ways, owing to the different interpretive and relational energies they bring to it.

Ute Röschenthaler's analysis of Chinese green tea in Mali reveals that it is more than a commodity that is traded between China and Mali. Embedded 
within the commodity are also processes enabling cultural mobility and African agency that render the Global South a space that is engendered by Africans consuming, appropriating, and trading. Based on field research in Mali and other West African countries since 2005 and four trips to China since 2014, Röschenthaler provides a history of green tea's introduction to Mali (beginning from the family tea gardens in China to the ports and through the Sahara before finally arriving in Mali) that also demonstrates how the commodity acquires its global characteristic. The arrival of Chinese green tea in Mali spurred the creation of new styles of teapots and variant tea-drinking practices that adopted Chinese and local (Malian) features.

According to Röschenthaler's observations from fieldwork, there are similarities and differences in its consumption between Malians and Chinese that can offer a way to think about how commodities generate new cultural practices that are particular to the Global South. These practices, besides a particular taste of green tea, have continued to date, giving purpose to Malian tea traders to collaborate with Chinese partners in sourcing the commodity. Trade statistics, Röschenthaler points out, obscure the prominent role of African traders in the export of green tea from China. The Malians who succeed as tea traders not only know the local tastes and, thus, the type of tea leaves to source, but are also parts of national and transnational networks and have access to capital that allow them to move containers of tea on a regular basis.

Foregrounding Global South-driven historiographies of the world, Kwesi Djapong Lwazi Sarkodee Prah's article concludes the special issue. His paper explores the relationship between Chama Cha Mapinduzi (сCM) of Tanzania and the Communist Party of China (CPC) over the years, both during Tanzania's fight against colonial occupation, and Mwalimu Julius Nyerere's post-independence leadership of the country. Drawing from primary source materials such as interviews of key officials from the era, newspaper articles, journal articles, and secondary source material such as books from the period under analysis, Prah constructs a narrative that highlights the nature and character of the environment and the circumstances within which both Parties sought and commenced relations. He examines the role of socialist ideology in this relationship, and the changes and shifts that have happened to the relationship at different times depending on particular political developments that shape both the substance and direction of the diplomatic relationships between the two countries.

Prah's article reveals China's sincerity towards the welfare of African countries as evidenced by the support the CPC rendered Mwalimu Julius Nyerere, as he spearheaded the liberation of those African countries like Mozambique 
and South Africa that remained under colonial domination after many other countries had won their independence in the 196os. This is the kind of information that challenges the Eurocentric narrative that depicts China as an opportunistic, predatory dragon that is helping itself to African raw materials and markets, by showing that even before it rose to the political and economic prominence that it is enjoying today, it was already collaborating with African countries in the fight against European colonialism and capitalism-driven neo-colonialism.

To conclude, we hope that this special issue will contribute to ongoing debate on China-Africa relations, particularly in showing how the two entities can build on past and current engagements to produce more productive and critical programs that mutually benefit both. Where the articles highlight blind spots in the relationship, the idea is to provoke readers and policy makers to imagine creative ways of responding to these for a stronger South-South collaboration. For example, by examining relations between the СPC and ССм, Prah's article provides a grounded historical analysis that could serve as an important point of reference for government officials, academics, and civil servants seeking to understand the ideological and practical foundation of relations between the two states. Similarly, Hu, Huynh, Molebatsi and Huynh, and Röschenthaler's articles foreground the importance of analyzing dynamic sociocultural creations and synergies among grounded communities that reflect complex histories of engagement between mobile peoples of the South and are often undervalued in migration studies and policies. Kahyana's article extends the last point by insisting that official travel by government executives to different parts of the world should be of pedagogical value to the taxpayers. The impact of Nyondo's travelogue reveals that government officials need to reflect on what their visits to China mean to them and their departments, and what needs to be done to effect the recommendations they make beyond trying to "cut-and-paste" from China's book.

\section{T Tu Huynh}

Associate Professor, School of International Studies/Academy of Overseas Chinese Studies, Jinan University, Guangzhou, China

huynh.2.t@gmail.com

\section{Danson Sylvester Kahyana}

Senior Lecturer, Department of Literature, Makerere University, Kampala, Uganda and Research Associate, English Department, Stellenbosch University, Stellenbosch, South Africa dkdan76@gmail.com /dkahyana@chuss.mak.ac.ug 


\section{Works Cited}

Adisu, Kinfu; Thomas Sharkey, and Sam C. Okoroafo. 2010. "The Impact of Chinese Investment in Africa." International Journal of Business and Management 5(9): 3-9. URL: www.ccsenet.org/ijbm.

Akyeampong, Emmanuel and Hippolyte Fofack. 2019. "Introduction: Special issue on 'Africa and China: Emerging patterns of engagement." Economic History of Developing Regions 34(3): 251-258. DOI: 10.1080/20780389.2019.1684691.

Alden, Chris. 2005. "China in Africa." Survival: Global Politics and Strategy 47(3):147-164. DOI: $10.1080 / 00396330500248086$.

Appadurai, Arjun. 1996. Modernity at Large: Cultural Dimensions of Globalization. Minneapolis: University of Minnesota Press.

Ayodele, Thompson and Olusegun Sotola. "China in Africa: An Evaluation of Chinese Investment." Initiative for Public Policy Analysis (IPPA) Working Paper Series. Retrieved from: http://www.ippanigeria.org/articles/China\%20-Africa\%2orelation _Workingpaper_final.pdf.

Brown, Keisha. 2016. "Blackness in Exile: W.E.B. DuBois's Role in the Formation of Representations of Blackness as Conceptualized by the Chinese Communist Party (CCP)." Phylon 53(2): 20-33. URL: https://www.jstor.org/stable/phylonig6o .53 .2 .20 .

Cheung, Yin-Wong; Jakob de Haan, Xingwang Qian, and Shu Yu. 2012. "China’s Outward Direct Investment in Africa." Review of International Economics 20(2): 201-220. DOI:10.1111/j.1467-9396.2012.01017.x.

Clarke, Marlea. 2018. "Global South: What Does It Mean and Why Use the Term?" Global South Political Commentaries. University of Victoria, Political Science. 8 August. Retrieved from: https://onlineacademiccommunity.uvic.ca/globalsouth politics/2018/08/o8/global-south-what-does-it-mean-and-why-use-the-term/.

Debrah, Emmanuel and Richard Asante. 2019. "Sino-Ghana Bilateral Relations and Chinese Migrants' Illegal Gold Mining in Ghana." Asian Journal of Political Science 27(3): 286-307. DOI: 10.1080/02185377.2019.1669473.

Dirlik, Arif. 2007. "Global South: Predicament and Promise." The Global South 1(1): 12-23. URL: http://www.jstor.org/stable/40339225.

Eom, Janet; Deborah Brautigam and Lina Benabdallah. 2018. "The Path Ahead:

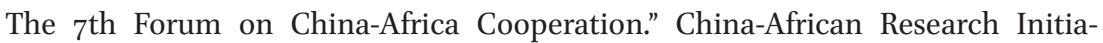
tive Briefing Paper, No. 1. Retrieved from: https://static1.squarespace.com/static/ 5652847de4bo33f56d2bdc29/t/5c467754898583fc9a99131f/1548121941093/Briefing +Paper+1+-+August+2018+-+Final.pdf.

Gukurume, Simbarashe. 2019. "Chinese Migrants and the Politics of Everyday Life in Zimbabwe." Asian Ethnicity 20(1): 85-102. DoI: 10.1080/14631369.2018.1490174. 
Haugen, Heidi Østbø. 2019. "China-Africa Exports: Governance Through Mobility and Sojourning." Journal of Contemporary Asia 49(2): 294-312. DOI: 10.1080/ 00472336.2018 .1517897 .

Kazanjian, David. 2016. The Brink of Freedom:Improvising Life in the Nineteenth-Century Atlantic World. Durham: Duke University Press.

Kusimba, Chapurukha; Tiequan Zhu and Purity Wakabari Kiura. 2020. China and East Africa: Ancient Ties, Contemporary Flows. London: Rowman \& Littlefield.

Lumumba-Kasongo, Tukumbi. 2007. "China-Africa Relations in the Post-Cold War Era: Dialectics of Rethinking South-South Dialogue," CODESRIA Bulletin, Numbers 1 and 2.

Lumumba-Kasongo, Tukumbi. 2011. "China-Africa Relations: A Neo-Imperialism or a Neo-Colonialism? A Reflection," African and Asian Studies 10: 234-266.

Mignolo, Walter. 2011. "The Global South and World Dis/Order." Journal of AnthropologicalResearch 67(2):165-188. uRL:https://www.jstor.org/stable/41303282.

Obeng, Mark Kwaku Mensah. 2019. "Journey to the East: A Study of Ghanaian Migrants in Guangzhou, China." Canadian Journal of African Studies/Revue canadienne des études africaines 53(1): 67-87. DOI: 10.1080/00083968.2018.1536557.

Oke, Muritala Oluseyi; Oshinfowokan and Olubunmi Okonoda. 2019. "Nigeria-China Trade Relations: Projections for National Growth and Development." International Journal of Business and Management 14(11): 77-89. UR L: ijbm.ccsenet.org.

Pratt, Mary Louise. 1992. Imperial Eyes: Studies in Travel Writing and Transculturation. London: Routledge.

Regissahui, Magby Henri Joel. 2019. "Overview on the China-Africa Trade Relationship.” Open Journal of Social Sciences 7: 381-403. DOI: 10.4236/jss.2019.77032.

Yang, Tangxiao. 2019. "Export, Employment, or Productivity? Chinese Investments in Ethiopia's Leather and Leather Product Sectors." China-African Research Initiative Briefing Paper, No. 39. Retrieved from: https://staticı.squarespace.com/static/

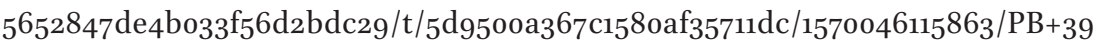
+-+Tang-+Leather+Ethiopia.pdf. 